\title{
Weight management: a comparison of existing dietary approaches in a work-site setting
}

\author{
WS Leslie ${ }^{1 *}$ MEJ Lean ${ }^{1}$, HM Baillie $^{2}$ and CR Hankey ${ }^{1}$ \\ ${ }^{1}$ University of Glasgow Department of Human Nutrition, Glasgow Royal Infirmary, Glasgow, UK ; and ${ }^{2}$ Robertson Centre for \\ Biostatistics, University of Glasgow, Glasgow, UK
}

OBJECTIVES: (1) To compare the effectiveness a $2512 \mathrm{~kJ}$ (600 kcal) daily energy deficit diet (ED) with a $6279 \mathrm{~kJ}$ (1500 kcal) generalized low-calorie diet (GLC) over a 24 week period (12 weeks weight loss plus 12 weeks weight maintenance). (2) To determine if the inclusion of lean red meat at least five times per week as part of a slimming diet is compatible with weight loss in comparison with a diet that excludes lean red meat.

DESIGN: Randomized controlled trial.

SETTING: Large petrochemical work-site.

PARTICIPANTS: One-hundred and twenty-two men aged between 18 and $55 \mathrm{y}$.

MAIN OUTCOME MEASURES: Weight loss and maintenance of weight loss.

INTERVENTION: Eligible volunteers were randomized to one of the four diet/meat combinations (ED meat, ED no meat, GLC meat, GLC no meat). One-third of subjects in each diet/meat combination were randomized to an initial control period prior to receiving dietary advice. All subjects attended for review every 2 weeks during the weight loss period. For the 12 week structured weight maintenance phase, individualized energy prescriptions were re-calculated for the ED group as 1.4 (activity factor) $\times$ basal metabolic rate. Healthy eating advice was reviewed with subjects in the GLC group. All subjects were contacted by electronic mail at 2 week intervals and anthropometric and dietary information requested.

RESULTS: No difference was evident between diet groups in mean weight loss at 12 weeks (4.3 (s.d. 3.4) kg ED group vs 5.0 (s.d. 3.5) kg GLC group, $P=0.34$ ). Mean weight loss was closer to the intended weight loss in the $2512 \mathrm{~kJ}(600 \mathrm{kcal}) \mathrm{ED}$ group. The dropout rate was also lower than the GLC group. The inclusion of lean red meat in the diet on at least five occasions per week did not impair weight loss. Mean weight gain following 12 weeks weight maintenance was +1.1 (s.d. 1.8$) \mathrm{kg}, \mathrm{P}<0.0001$. No differences were found between groups.

CONCLUSIONS: This study has shown that the individualized $2512 \mathrm{~kJ}$ (600 kcal) ED approach was no more effective in terms of weight loss than the $6279 \mathrm{~kJ}(1500 \mathrm{kcal})$ GLC approach. However the ED approach might be considered preferable as compliance was better with this less demanding prescription. In terms of weight loss the elimination of red meat from the diet is unnecessary. The weight maintenance intervention was designed as a low-input approach, however weight regain was significant and weight maintenance strategies require further development.

International Journal of Obesity (2002) 26, 1469-1475. doi:10.1038/sj.ijo.0802153

Keywords: individualized energy deficity; weight management; work-site; male; overweight/obesity

\section{Introduction}

Obesity is increasing in prevalence. ${ }^{1-3}$ Recent figures show that $62 \%$ of men and $54 \%$ of women are either overweight or obese. ${ }^{4}$ In addition to being a major health problem in its

*Correspondence: WS Leslie, University of Glasgow Department of Human Nutrition, Glasgow Royal Infirmary, Glasgow G31 2ER, UK. E-mail: ws12n@clinmed.gla.ac.uk

Received 5 November 2001; revised 11 June 2002;

accepted 14 June 2002 own right, obesity is associated with a range of serious symptoms and many other co-morbid conditions such as NIDDM, hypertension and hyperlipidaemia. These in turn, are all established risk factors for coronary heart disease. The estimated cost to the health service of obesity and related conditions is immense. ${ }^{5}$

It is recognized that moderate weight loss, rather than the pursuit of thinness, leads to reduced risk of co-morbid diseases and lowering of coronary risk factors ${ }^{6-9}$. At present the management of overweight within the health service in the UK is ad-hoc and fragmented ${ }^{10}$ with no single evidence- 
based dietary method for weight management being used in clinical practice. Current clinical guidelines for the management of obesity in Scotland ${ }^{2}$ recommends a 12 week weight loss period using a $2512 \mathrm{~kJ} / 600 \mathrm{kcal}$ daily energy deficit in a multi-dimensional approach to achieve moderate weight loss, followed by a structured plan for weight maintenance. The extensive literature on weight management includes only one small non-randomized audit that compared the $2512 \mathrm{~kJ}(600 \mathrm{kcal})$ approach with another fixed $5023 \mathrm{~kJ}$ $(1200 \mathrm{kcal})$ diet. $^{11}$ Although the importance of a 12 week maintenance period is also emphasized in the SIGN publication, ${ }^{2}$ little scientific evidence exists to show how this is best achieved and thus health service providers have not yet addressed it.

The value, for health reasons and to help weight control, of reducing fat intake appears to be known but not fully understood or correctly implemented by a large proportion of the population. It would appear that many feel there is a need to reduce or even eliminate red meat from their diets.

The hypotheses to be tested by the present study were: (1) that a $2512 \mathrm{~kJ}(600 \mathrm{kcal})$ daily energy deficit approach (ED) was more effective in achieving and maintaining weight loss than a generalized low calorie diet $(6279 \mathrm{~kJ} / 1500 \mathrm{kcal}$; GLC) over a 12 week weight loss period followed by a 12 week weight maintenance period; (2) that the inclusion of lean red meat at least five times per week as part of a slimming diet was compatible with weight loss in comparison with a diet that excludes it.

\section{Methods}

\section{Study design}

The study used a randomized-controlled design with a blinded envelope system for treatment allocation. Eligible volunteers were individually randomized to one of the four diet/meat combinations (ED meat, ED no meat, GLC meat, GLC no meat). Within the randomization system one-third of the subjects in each diet/meat combination were randomized to an initial control period prior to receiving dietary advice.

\section{Subjects/recruitment}

Subjects were recruited from a large industrial work-site employing a cross-section of staff. Recruitment was carried out using electronic mail (e-mail). A site-wide e-mail message advertised the study and requested volunteers. Interested subjects were asked to reply via e-mail and provide their height, weight and waist measurement to assess eligibility for entry into study. Exclusion criteria were body mass index (BMI) below $25 \mathrm{~kg} / \mathrm{m}^{2}$, under supervision by the work-site medical officer, diabetes treated with insulin, any other condition requiring prescribed food products or specialist dietary intervention, or intentional weight loss $>3 \mathrm{~kg}$ in previous 3 months.
Eligible subjects were e-mailed a brief description of the study and invited to participate. All subjects gave written informed consent before entry into the study. Ethical Approval was obtained from Forth Valley Health Board Ethics Committee.

\section{Diet intervention}

Subjects' randomized to receive the ED diet received individualized energy prescriptions calculated using Schofield equations $^{12}$ to calculate basal metabolic rate (BMR), taking into account the age, gender, and body weight of the individual. An additional activity factor of $1.3 \times$ BMR was then applied to calculate energy required to remain weight stable. As the aim was to induce weight loss, $2512 \mathrm{~kJ}$ (600 kcal) was subtracted from each individual's estimated daily energy requirements. All subjects randomized to receive the GLC diet were given a $6279 \mathrm{~kJ}(1500 \mathrm{kcal})$ eating plan.

Macronutrient composition of the eating plans in both groups was designed to provided greater than 50\% energy from carbohydrate, less than 35\% energy from total fat and under $20 \%$ from protein. ${ }^{13}$ Advice was also given to restrict or avoid alcohol consumption.

\section{Detailed dietary advice}

An eating plan employing standardized principles has been devised within the Department of Human Nutrition and used in previous weight management studies. ${ }^{14}$ The plan is based on an exchange system for three groups of food 'bread', 'meat' and 'fruit'. The 'bread' exchanges comprise foods rich in complex carbohydrates such as bread, cereals, rice, pasta and potatoes. The 'fruit' exchanges are rich in carbohydrate and will provide the main source of simple sugars. All subjects were encouraged to increase their consumption towards the dietary compositional targets. ${ }^{13}$ Individual energy prescriptions ranging from a minimum of $5023 \mathrm{~kJ}(1200 \mathrm{kcal})$ to a maximum $10884 \mathrm{~kJ}(2600 \mathrm{kcal})$ daily have been calculated in increments of $419 \mathrm{~kJ}$ (100 kcal) per day using various combinations of these exchanges. The eating plan allows the daily consumption of red meat. Participants randomized to include red meat at least five times per week were advised to consume this in the form of quality lean cuts. Prior to the commencement of this study the eating plan was revised to provide a plan which excluded red meat. Fish, eggs and cheese were included as acceptable alternatives in the 'meat' exchange category of the eating plan.

A minimum of $60 \mathrm{~min}$ was allowed for the initial dietetic consultation in which the weight loss intervention was explained to each participant individually. All subjects were seen on a one-to-one basis every 2 weeks during the 12 week weight loss period and these consultations were of approximately 15-20 min duration. Subjects unable attend all appointments were allowed a maximum of two review consultations using e-mail contact. 


\section{Maintenance period}

The differences in treatments between the groups were continued during the 12 week structured weight maintenance period. For the ED group, the individualized energy prescriptions were re-calculated. An activity factor of 1.4 was applied to the estimated BMR, reflecting the energy requirements for weight stability, rather than weight loss.

Healthy eating advice was reviewed with subjects in the GLC group. During the 12 week maintenance period all subjects were contacted by e-mail at 2 week intervals (five occasions). Each e-mail contact used a structured format. Subjects were asked to complete a short eating habits questionnaire (Appendix 1), and provide a current weight and waist circumference measurement. Any problems encountered by subjects during the weight maintenance period were discussed and addressed within the e-mail contacts. Face to face consultations were discouraged in order to test the effectiveness of the e-mail contact.

\section{Measurements and follow-up}

Physical/anthropometric

All subjects had measurements of height, weight, waist circumference and fasting plasma lipids taken.

\section{Dietary}

Dietary practices were assessed using the Dietary Targets Monitor, ${ }^{15}$ a validated short food frequency questionnaire developed for use in the Scottish Health Survey. All measurements were taken at baseline and repeated at weeks 12 and 24

\section{Statistical analysis}

A study based on 84 analysable subjects was estimated to have power of at least $80 \%$ to detect statistically significant differences in outcome measures between the diets of the order of 0.8 standard deviations. These calculations incorporate Bonferroni correction to allow for multiple analyses. Anticipating a dropout rate of 30\%, 120 subjects were sought.

Statistical analysis was performed using the software packages SAS for Windows (Version 8.0) and SPSS for Windows (Version 8.0). Comparisons between the diet groups were made at 12 and 24 weeks using two sample $t$-tests and corresponding 95\% confidence intervals. Paired $t$-test analysis was used to examine within group differences at 12 and 24 weeks. Two-way analysis of variance techniques were also used to examine the effects of both dietary approaches and meat advice. Regression analysis was used to assess the relationship between weight change and energy prescription, and weight change and energy deficit. Weight loss for the control group was compared to two dietary programmes using analysis of variance techniques and corresponding $95 \%$ confidence intervals. The assumptions of normality required for these analyses were checked and appeared to be valid. Reasons for withdrawal from the study were examined using Fishers Exact test.

\section{Results}

One-hundred and twenty-two men aged $18-55 \mathrm{y}$ were recruited to the study. Twelve subjects withdrew their participation prior to dietary advice being given (seven control subjects). A further 19 subjects withdrew during the weight loss period, 15 from the GLC group and four from the ED group $(P=0.004)$. Reasons for withdrawal included: not attending appointments, six (ED one, GLC five); inability to follow diet, five (ED two, GLC three); work commitments, two; retired from company, one; relocation, one; bereavement, one, and loss of interest following holiday, three. No between-group differences were evident in the reasons for withdrawal $(P=0.16)$.

In the ED group daily energy prescriptions ranged from $7116 \mathrm{~kJ}(1700 \mathrm{kcal})$ to $10884 \mathrm{~kJ}(2600 \mathrm{kcal})$ per day with around one-third of participants (37\%) prescribed $7953 \mathrm{~kJ}$ $(1900 \mathrm{kcal})$ per day. Mean daily energy deficit was $4536 \mathrm{~kJ}$ (1084 kcal) in the GLC diet group, range $3349 \mathrm{~kJ}(800 \mathrm{kcal})$ to $7535 \mathrm{~kJ}(1800 \mathrm{kcal})$ per day.

Physical and anthropometric measurements

Following randomization the physical characteristics of the two groups were similar (Table 1). Two-way analysis of variance, carried out determine the effect of the inclusion or exclusion of red meat on weight loss, showed that meat advice did not qualitatively effect weight loss or changes in biochemical measurements. Results are therefore presented for the two sample $t$-tests comparing the ED and GLC dietary approaches.

\section{Weight loss}

Control group. The weight of the subjects assigned to the 12 week control period remained stable. This is in contrast to the ED and GLC groups who both had a significant mean weight loss at week 12 (Table 2). Weight change in the two diet groups differed significantly from that of the control group (Table 3).

Table 1 Comparison of physical, anthropometric and biochemical measurements between diet groups at baseline

\begin{tabular}{lcc}
\hline & $E D(\mathrm{n}=61)$ & $G L C(\mathrm{n}=61)$ \\
\hline Age & $41.3(8.1)$ & $42.1(7.8)$ \\
BMI & $31.5(3.7)$ & $30.4(3.7)$ \\
Weight $(\mathrm{kg})$ & $98.2(13.9)$ & $94.6(13.3)$ \\
Waist $(\mathrm{cm})$ & $108.4(9.3)$ & $105.9(9.3)$ \\
Total cholesterol (mmol/l) & $5.4(1.0)$ & $5.7(1.0)$ \\
HDL (mmol/l) & $1.2(0.3)$ & $1.3(0.3)$ \\
LDL (mmol/l) & $3.2(0.8)$ & $3.5(1.0)$ \\
Triglyceride (mmol/l) & $2.1(1.7)$ & $1.9(1.0)$ \\
\hline
\end{tabular}

All data expressed as mean and (s.d.). $n=$ maximum number in each group. 
Intention-to-treat analysis. Weight loss data were examined in two ways, firstly on an intention to treat basis and then for those who completed the 12 week weight loss period. Intention to treat analysis used the last recorded weight, where available, for those who dropped out. If the only recorded weight was that at baseline, zero weight loss was assumed.

Analysis showed a 4\% reduction in mean body weight for the study population as a whole. Mean weight was reduced from 96.4 (s.d. 13.6) $\mathrm{kg}$ at baseline to 92.6 (s.d. 14.0) $\mathrm{kg}$ at week $12, P<0.0001$. Comparative analysis showed no statistically significant difference in mean weight loss between the ED and GLC group, respectively (3.7 (s.d. 3.4) vs 3.9 (s.d. 3.5) kg, $P=0.78)$.

'Completers'analysis. Ninety-one men completed the 12 week weight loss period. Weight loss was significant in all groups (Table 4). As in the intention to treat analysis no difference was evident between the diet groups in mean weight loss (Table 5).

Nine subjects (10\%) lost no weight during the weight loss period. Of the 82 subjects who lost weight 37 (45\%) lost $0-5 \%$ of initial body weight. Thirty-eight men (46\%) lost between 5 and $10 \%$, with $9 \%$ achieving a $10 \%$ or greater

Table 2 Mean (s.d.) change in weight for control group and diet groups between baseline and week 12

\begin{tabular}{lccc}
\hline Diet/group & $\mathrm{n}$ & $\begin{array}{c}\text { Weight change }(\mathrm{kg}) \\
(0-12 \text { weeks })\end{array}$ & $P$ \\
\hline Control & 44 & $0.5(2.2)$ & 0.15 \\
Energy deficit & 40 & $-4.6(3.4)$ & $<0.0001$ \\
Generalized low calorie & 38 & $-5.6(3.7)$ & $<0.0001$ \\
\hline
\end{tabular}

Table 3 Comparison of mean weight change between control group and diet groups from baseline to week 12

\begin{tabular}{|c|c|c|c|}
\hline Difference & $\begin{array}{c}\text { Mean } \\
\text { difference (s.e.) }\end{array}$ & $95 \% \mathrm{Cl}$ & $P$ \\
\hline Control-ED & $5.2(0.7)$ & $3.7-6.6$ & $<0.0001$ \\
\hline Control-GLC & $6.2(0.8)$ & $4.6-7.7$ & $<0.0001$ \\
\hline $\mathrm{ED}-\mathrm{GLC}$ & $1.0(0.8)$ & $-0.6-2.5$ & 0.22 \\
\hline
\end{tabular}

$\mathrm{ED}=$ energy deficit; $\mathrm{GLC}=$ generalized low calorie. weight loss. Comparisons between the ED and GLC group showed no difference in terms of percentage weight loss.

\section{Relationship between achieved weight loss, energy prescription and deficit}

Analysis of data showed no relationship between weight loss and actual energy prescription in the ED group $(P=0.83$; Figure 1). Similarly in the GLC diet group no relationship was evident between daily energy deficit and actual weight loss $(P=0.52$; Figure 2$)$.

\section{Weight maintenance}

Eighty-five subjects completed the full 24 week programme. Mean weight gain was significant in all groups (Table 4). No significant difference was evident between the ED and GLC groups in weight gain $(P=0.27)$. Mean weight remained significantly lower than at baseline in both the ED and GLC groups, ED 92.0 (s.d. 12.8) kg, $P<0.003$, GLC group 90.4 (s.d. 12.6) kg, $P<0.0001$.

Of those who lost weight $(n=77)$ during the initial 12 week period, two remained weight stable and 17 lost more weight between weeks 12 and 24 . The remaining 58 subjects regained weight. Of these $36(62 \%)$ maintained up to $50 \%$ of their weight loss and 17 (29\%) regained more than 50\% of the weight they had lost. Only five (9\%) regained all of their original weight loss.

\section{Plasma lipids}

At 12 weeks total, LDL cholesterol and triglyceride concentrations were significantly reduced in the study population as a whole. No significant differences were evident between either diet group in the changes, from baseline, in plasma lipid concentrations (Table 5).

On completion of weight maintenance triglyceride concentrations remained significantly reduced in the study population as a whole $(P=0.003)$, and there was a significant rise in HDL concentrations $(P=0.04)$. As in the weight loss period no between group differences were evident in the changes from weeks 12 to 24 in lipid concentrations.

Table 4 Mean (s.d.) change in weight by diet and meat/no meat group for those who completed the weight loss and weight maintenance periods

\begin{tabular}{|c|c|c|c|c|c|c|}
\hline \multirow[b]{2}{*}{ Group } & \multicolumn{3}{|c|}{ Weight loss period ( $0-12$ weeks) } & \multicolumn{3}{|c|}{ Weight maintenance period (12-24 weeks) } \\
\hline & $\mathrm{n}$ & Weight change & $\mathrm{P}$ & $\mathrm{n}$ & Weight change & $\mathrm{P}$ \\
\hline All subjects & 91 & $-4.6(3.5)$ & $<0.0001$ & 85 & $1.1(1.8)$ & $<0.0001$ \\
\hline Energy deficit & 49 & $-4.3(3.4)$ & $<0.0001$ & 45 & $0.9(2.0)$ & 0.003 \\
\hline Generalized low calorie & 42 & $-5.0(3.5)$ & $<0.0001$ & 40 & $1.4(1.6)$ & $<0.0001$ \\
\hline Meat & 45 & $-4.2(3.7)$ & $<0.0001$ & 43 & $0.9(1.6)$ & 0.001 \\
\hline No meat & 46 & $-5.0(3.2)$ & $<0.0001$ & 42 & $1.4(2.0)$ & $<0.0001$ \\
\hline
\end{tabular}


Table 5 Changes from baseline to week 12 in physical, anthropometric and biochemical measurements for subjects who completed the weight period

\begin{tabular}{|c|c|c|c|c|c|c|}
\hline & \multirow[b]{2}{*}{ All subjects $(\mathrm{n}=91)$} & \multirow[b]{2}{*}{$E D(n=49)$} & \multirow[b]{2}{*}{$G L C(n=42)$} & \multicolumn{3}{|c|}{$\begin{array}{l}\text { Significance of change in ED } \\
\text { group vs change in GLC group }\end{array}$} \\
\hline & & & & $\mathrm{P}$ & 95\% lower $\mathrm{Cl}$ & $95 \%$ upper $\mathrm{Cl}$ \\
\hline $\mathrm{BMI}\left(\mathrm{kg} / \mathrm{m}^{2}\right)$ & $-1.5(1.1)^{\star \star \star}$ & $-1.4(1.1)^{\star \star *}$ & $-1.6(1.1)^{\star \star *}$ & 0.31 & -0.2 & 0.7 \\
\hline Weight (kg) & $-4.6(3.5)^{\star \star *}$ & $-4.3(3.4)^{\star \star \star}$ & $-5.0(3.5)^{\star \star \star}$ & 0.34 & -0.8 & 2.1 \\
\hline Waist $(\mathrm{cm})$ & $-4.9(3.4)^{\star \star *}$ & $-4.7(3.4)^{\star \star *}$ & $-5.2(3.4)^{\star * *}$ & 0.48 & -0.9 & 1.9 \\
\hline Total cholesterol $(\mathrm{mmol} / \mathrm{l})$ & $-0.3(0.6)^{\star \star \star}$ & $-0.2(0.6)^{\star}$ & $-0.34(0.5)^{\star \star \star}$ & 0.40 & -1.1 & 0.3 \\
\hline $\mathrm{HDL}(\mathrm{mmol} / \mathrm{l})$ & $-0.007(0.2)$ & $0.005(0.1)$ & $-0.02(0.2)$ & 0.51 & -0.06 & 0.1 \\
\hline LDL (mmol/l) & $-0.2(0.5)^{\star \star}$ & $-0.09(0.5)$ & $-0.2(0.5)^{\star}$ & 0.19 & -0.08 & 0.4 \\
\hline Triglyceride (mmol/l) & $-0.2(0.8)^{\star}$ & $-0.2(0.8)$ & $-0.2(0.8)$ & 0.96 & -0.3 & 0.3 \\
\hline
\end{tabular}

All data expressed as mean and (s.d.). $n=$ maximum number in each group.

${ }^{* * *} P<0.0001,{ }^{* *} P<0.01,{ }^{*} P<0.05$

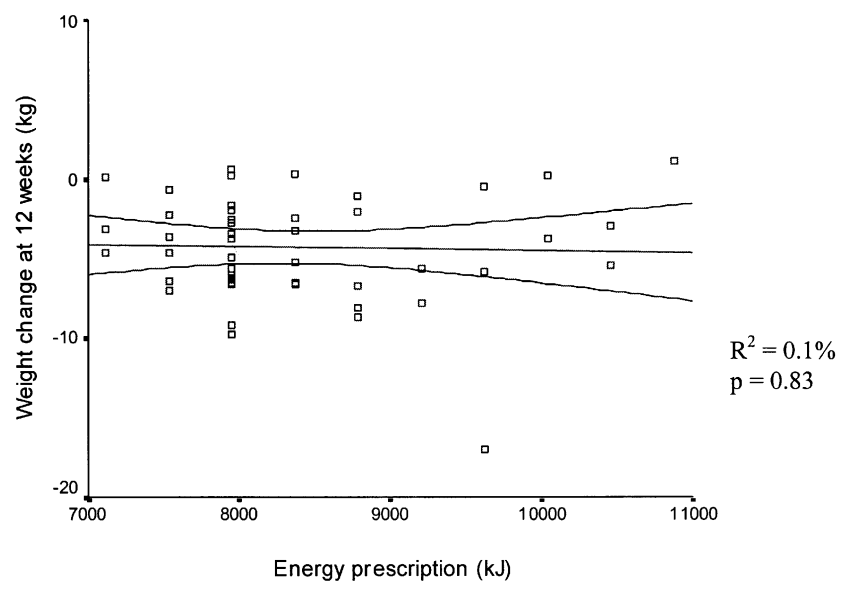

Figure 1 Relationship between weight change and energy prescription

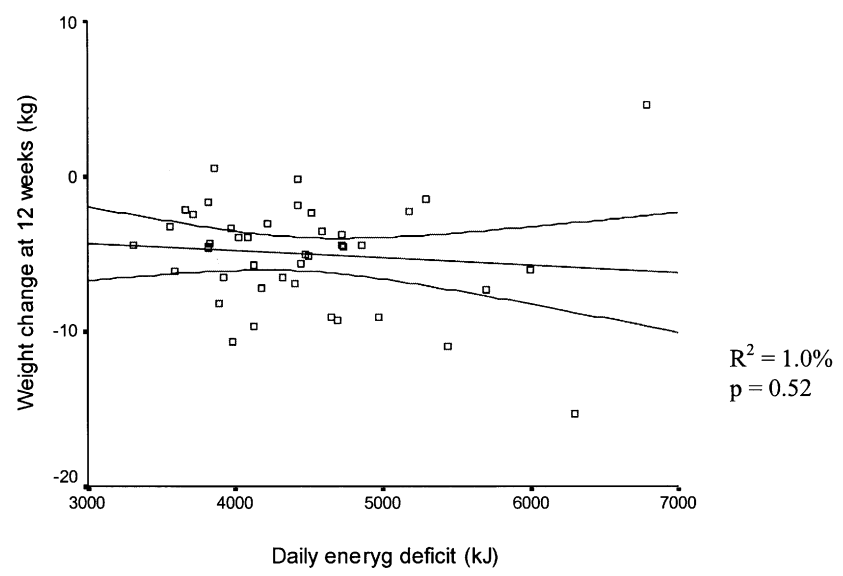

Figure 2 Relationship between weight change and daily energy deficit in the GLC group.

\section{Discussion}

The development of strategies for the prevention and treatment of obesity is now a priority for health promotion and education. ${ }^{2,16}$ There is no one method of weight loss which will suit all ${ }^{17}$ and 'successful weight loss is achievable through a variety of methods' ${ }^{18}$ A huge literature of lay books exists, but they promote variable and often ill-advised methods. ${ }^{19}$ Among health professionals, there is uncertainty as to which interventions are proven to be effective ${ }^{5}$ and there is a need provide scientifically evaluated evidence regarding the efficacy of different approaches to weight loss.

The $2512 \mathrm{~kJ}$ (600 kcal) daily energy deficit approach advocated in Scotland's National Guidelines for weight management ${ }^{2}$ was theoretically based. ${ }^{20}$ It was supported by only one very small non-randomized audit, ${ }^{11}$ which suggested greater compliance with an individually designed energy deficit diet than with a standard $5023 \mathrm{~kJ}(1200 \mathrm{kcal})$ diet. The present study makes a clinically important comparison between two widely used dietary methods using a randomized-controlled design and provides evidence to guide practice.

\section{Weight loss}

Weight change is an accepted measure of assessing compliance with dietary advice. ${ }^{21}$ This is especially true in freeliving subjects when it is not possible to accurately monitor the two main factors that may affect weight loss, dietary intake and energy expenditure. For the dietary approaches in the present study predicted weight loss was calculated using standard equations which calculate basal metabolic rate and an activity factor to predict total energy expenditure. ${ }^{12}$ Total compliance over a 12 week period, with a daily energy deficit of $2512 \mathrm{~kJ}(600 \mathrm{kcal})$ should result in approximately $6-7 \mathrm{~kg}$ weight loss. ${ }^{2}$ Expected weight loss in the GLC group, calculated using mean daily energy deficit should be around $13 \mathrm{~kg}$. In the present study actual weight loss was closer to the expected weight loss in the ED group than in the GLC group, suggesting that adherence with dietary advice was better in the ED group. 
The weight loss achieved in both groups was similar. As intended, given the uniformity of the prescribed daily deficit, the range of weight losses was small across the range of energy prescriptions in the ED group. In the GLC group the range of daily energy deficits varied widely and so therefore should weight loss, with greater weight loss resulting from a greater energy deficit. Weight loss was in fact similar across the range of daily energy deficits which also suggests that adherence to dietary advice was possibly poorer in the GLC group.

It is suggested that 'a lower dropout rate represents some form of success, and that any program that can achieve a lower dropout rate will be successful' ${ }^{21}$ During the weight loss period of the present study significantly more subjects dropped out of the GLC group than the ED group. However we are unable to confirm that the lower attrition rate was an indicator of greater acceptability with dietary advice in the ED group as no between-group differences were found in the reasons given for withdrawal.

Our data provide support for the view of Frost et $a l^{11}$ and Lean and James ${ }^{20}$ that greater prescribed energy deficit does not lead to greater weight loss and that compliance with dietary advice may be better when energy deficit is moderate.

The benefits of moderate weight loss between 5 (5\%) and $10 \mathrm{~kg}(10 \%)$ are well documented. ${ }^{6-9}$ Only a small percentage of subjects in the present study achieved $10 \%$ weight loss. For the majority of people this target may not be achievable over a 12 week period given that the subjects in the present study were well motivated and their participation did not inconvenience them greatly, as consultations were at their place of employment.

The belief that red meat is 'high in fat' means that for many, self-directed attempts at 'dieting' are synonymous with the exclusion of red meat from their diet. The present study provides evidence that weight loss and improvements in plasma lipids are achievable with a diet that includes regular consumption of lean red meat. Over the last two decades the fat content of meat has fallen and a large proportion of the fat content of meat is unsaturated. ${ }^{22}$ Overall red meat and meat products usually contribute no more than one-quarter of the total fat intake of all foods eaten at home $^{23}$ and in terms of weight loss and improvements in plasma lipids the elimination of red meat from the diet is unnecessary.

\section{Weight maintenance}

Weight management studies have demonstrated the maximum period over which weight will continue to be lost is usually around 12 weeks. ${ }^{2}$ Subjects in the present study were often reluctant to discontinue active weight loss after 12 weeks and commence weight maintenance. It may be that the period of active weight loss should be flexible and tailored to each individual dependent on their progress as imposing a strict protocol may have a negative effect on motivation and long-term outcomes. However failure is more commonly failure of maintenance than failure to secure some weight loss. ${ }^{24}$ There is clearly scope to improve the maintenance results in the present study. Continued face-to-face professional contact might have improved the results, but there is no benchmark of good practice for comparison.

\section{Merits of workplace for intervention}

Given the large numbers of overweight and obese subjects it has been recommended that management should be undertaken in primary health care, community or commercial sectors. ${ }^{2}$ Within these categories, the work-place has shown promise as a location for both health promoting activities and weight management programmes ${ }^{25,26}$ allowing access to new populations who may not otherwise seek weight loss advice. $^{25}$

The subjects in the present study were male and most had never previously undertaken any formal programme of weight management. This is in contrast to the usual female majority seeking weight loss advice or volunteering for trials. ${ }^{27,28}$ Men, in general, are characterized by central fat distribution which significantly increases their cardiovascular risk, ${ }^{28}$ demanding greater priority for treatments. ${ }^{29}$ At baseline, prior to intervention, the mean waist circumference of these male subjects exceeded the 'action level 2' cutoff of $102 \mathrm{~cm} .{ }^{8}$ The location of our study therefore not only accessed a population new to weight management but also one at high cardiovascular risk.

Dietary advice was delivered using a one-to-one approach. A group approach, recommended in the SIGN guidelines, ${ }^{2}$ would have been impractical due to the working patterns of the subjects. However previous research reports a better and more sustained effect achieved by individual counselling particularly in men'. ${ }^{30}$ Anecdotally the men reported that this approach was an important factor in their participation.

\section{Conclusion}

This study has shown that the $2512 \mathrm{~kJ}$ ( $600 \mathrm{kcal})$ ED individualized approach was no more effective in terms of weight loss than a blanket $6279 \mathrm{~kJ}(1500 \mathrm{kcal})$ approach with a large prescribed energy deficit. However, compliance with advice appeared to be better with the individualized approach. As with any form of treatment, compliance is a key issue in weight management. Good compliance may not only optimize weight loss but may be more likely to lead to long-term changes in dietary habits, thus improving the likelihood of maintaining weight loss and improving long term health. The $2512 \mathrm{~kJ} / 600 \mathrm{kcal}$ individualized ED approach is no harder or more time-consuming to use and should be the preferred method for routine practice. The regular consumption of lean red meat on at least five occasions per week did not impair weight loss or maintenance. This reinforces the promotion of the principles of healthy eating on which any weight-reducing diet ought to be based. 
Weight maintenance appears more difficult than weight loss. The present weight maintenance intervention was designed to reduce the role of the therapist in weight management, and ultimately increase the individual's responsibility to self-monitor using e-mail. However, weight regain was considerable over 12 weeks so weight maintenance strategies require further research.

\section{Acknowledgements}

We thank BP Grangemouth for giving us access to their work force, and the staff of their Occupational Health Department for their continued support and co-operation throughout the study. This study was funded by the Meat and Livestock Commission.

\section{References}

1 Nutrition and Physical Activity Task Force of the Department of Health. Reversing the increasing problem of obesity in England. Department of Health: London; 1995.

2 Scottish Intercollegiate Guidelines Network. Obesity in Scotland. Integrating prevention with weight management. Scottish Intercollegiate Guidelines Network: Edinburgh; 1996.

3 WHO. Obesity, preventing and managing the global epidemic, Report of a WHO Consultation on Obesity. World Health Organization: Geneva; 1998.

4 The Scottish Health Survey 1998. HMSO: London; 2000.

5 National Audit Office. Tackling obesity in England. The Stationery Office: London; 2001.

6 UK PDS. Prospective diabetes study 7. Response of fasting plasma glucose to diet therapy in newly presenting type II diabetic patients. Metab Clin Exp 1990; 39: 905 - 912.

7 Goldstein DJ. Beneficial health effects of modest weight loss. Int J Obes 1992; 16: $397-415$

8 Han TS, van Leer EM, Seidell JC, Lean MEJ. Waist circumference action levels in the identification of cardiovascular risk factors: prevalence study in a random sample. Br Med J 1995; 311: $1401-1405$

9 Lean MEJ, Han TS, Morrison CE. Waist circumference indicates the need for weight management. Br Med J 1995; 311: 158-161.

10 Buttriss JL. Food and nutrition: attitudes, beliefs, and knowledge in the United Kingdom. Am J Clin Nutr 1997; 65: 1985S-95S

11 Frost G, Masters K, King C, Kelly M, Hasan U, Heavens P, White R, Stanford J. A new method of energy prescription to improve weight loss. J Hum Nutr Diet 1991; 4: 369-374.

12 Schofield WN, Schofield C, James WPT. Basal metabolic ratereview and prediction, together with annotated bibliography of source material. Hum Nutr Appl Nutr 1985; 39C: 5-96.

13 Committee on the Medical Aspects of Food Policy. Dietary reference values for food energy and nutrients for the United Kingdom, Report 41. HMSO: London; 1991.

14 Hankey CR, Rumley A, Lowe GDO, Woodward M, Lean MEJ. Moderate weight loss improves red cell aggregation and factor VII activity in overweight subjects. Int J Obes Relat Metab Disord 1997; 21: $644-650$
15 Lean MEJ, Eley S, Anderson AS, Morrison C, Bolton-Smith C. Evaluation of the Scottish Health Survey Eating Habits Questionnaire to monitor Scottish Diet food targets. (Abstract.). Proc Nut Soc 1998; 57(4): 136a.

16 The health of the nation. HMSO: London; 1992.

17 Lean MEJ. Clinical handbook of weight management. Dunitz: London; 1998.

18 Klem ML, Wing RW, McGuire MT, Seagle HM, Hill JO. A descriptive study of individuals successful at long-term maintenance of substantial weight loss. Am J Clin Nutr 1997; 66: 239-246.

19 The Consumers Association. Balancing the books, choosing and using diets. Which 2001; May: 34-37.

20 Lean MEJ, James WPT. Prescription of diabetic diets in the 1980s. Lancet 29 March 1986; $723-725$

21 Rossner S.Factors determining the long-term outcome of obesity treatment: In: Bjorntorp P, Brodoff BN (eds). Obesity. Linincott: Philadelphia, PA; 1992Chap 61. pp 712-719.

22 British Nutrition Foundation. The nutritional contribution of meat to the British diet: recent trends and analyses. Nutr Bull 2001; 26: $283-293$.

23 Ministry of Agriculture Fisheries and Food. National food survey 1999. The Stationery Office: London; 2000.

24 Wadden TA, Sternberg JA, Letizia KA, Stunkard AJ, Foster GA Treatment of obesity by very low calorie diet, behaviour therapy, and their combination: a five year perspective. Int J Obes 1989; 13: $39-46$.

25 Hennrikus DJ, Jeffery RW. Worksite intervention for weight control: a review of the literature. Am J Hlth Prom 1996; 6: 471-498.

26 Health Education Board for Scotland. Scotland's health at work HMSO: Edinburgh; 1996.

27 White JH. The process of embarking on a weight control program. Hlth Care Women Int 1984; 5: 77-91.

28 Despres JP. Drug treatment for obesity. Br Med J 2001; 322: $1379-1380$.

29 Despres JP, Lemieux I, Prud'homme D. Treatment of obesity: need to focus on high risk abdominally obese patients. $\mathrm{Br}$ Med J 2001; 322: $716-720$.

30 Hakala P, Karvetti R, Ronnemaa T. Group vs individual weight reduction programmes in the treatment of severe obesity - a five year follow-up study. Int J Obes 1992; 17: 97-102.

\section{Appendix 1}

Electronic mail message sent to participants every 2 weeks during weight maintenance, requesting dietary and anthropometric information.

Weight...... Waist......

How many portions of fruit did you eat yesterday......

How many portions of vegetables did you eat yesterday......

Is this your usual amount of fruit and vegetables, less or more than usual......

What foods are you eating as snacks......

Have you increased the number of take away meals or meals out since the end of the weight loss period...... 